\title{
A mitologia grega (1803-1804) ${ }^{1}$
}

Friedrich Schlegel

Constantino Luz de Medeiros (Trad.)

Universidade Federal de Minas Gerais, Belo Horizonte, Minas Gerais / Brasil constantinoluz@usp.br

A mitologia grega é dividida em duas épocas: a primeira abarca a mitologia homérica, a mais antiga que conhecemos, e da qual não se pode indicar a maioria das fontes; a segunda contém a história da introdução das divindades estrangeiras, com suas fábulas e lendas. O próprio modo de inserção [dessa mitologia] através de irmandades secretas e, por assim dizer, missionários, indica que ela era estrangeira e não nativa; pertencem a essa mitologia, por exemplo, o culto a Baco, o qual surge em uma época tardia, a partir da Frígia, e o culto a Ísis, tomado de empréstimo dos egípcios em uma época ainda mais tardia, e, principalmente, os Mistérios de Deméter, em Elêusis. Na verdade, nessa época também seria preciso mencionar a relação entre os filósofos e a mitologia, pois ou eles a rejeitavam inteiramente, ou buscavam dar-lhe uma interpretação elevada. Por essa razão, nosso objetivo não pode ser o de caracterizar detalhadamente a mitologia grega; o que devemos fazer aqui é uma caracterização, uma verificação e um ajuizamento geral sobre o conceito de mitologia.

\footnotetext{
${ }^{1}$ Tradução de „Die griechische Mythologie (1803-1804)“, publicado em Schriften und Fragmente: Ein Gesamtbild seines Geistes, obra de Friedrich Schlegel editada por Ernst Behler e publicada pela Alfred Kröner Verlag em 1956. Destaca-se, desde já, que os grifos presentes no texto, salvo aqueles que vêm nos termos em alemão, são do autor.
} 
O conceito geral de mitologia, sobre o qual todos estão de acordo, é uma mistura de história, lendas reproduzidas oralmente, simbologia, e poesia acrescentada arbitrariamente. Apenas sobre a origem da mitologia e o modo de interpretá-la é que se tem opiniões diferentes. Alguns desejam interpretá-la de um modo inteiramente histórico, outros, de um modo totalmente alegórico; já entre os antigos é possível encontrar essas duas perspectivas divergentes. Considerar apenas uma dessas perspectivas leva a uma grande parcialidade. Assim como é inegável que a antiga mitologia contenha alusões às forças da natureza, como, por exemplo, ao sistema dos planetas, também é inegável que se possa encontrar nela tradições realmente antiquíssimas das condições primitivas dos homens, das ações maravilhosas de heróis grandiosos, das migrações de inúmeros povos, assim como da fundação e do desaparecimento de reinos grandes e poderosos. Todavia, mesmo que ambas as perspectivas [a histórica e a alegórica] sejam combinadas, ainda assim não será suficiente; é preciso que uma terceira perspectiva, a filosófica, seja acrescentada: a mitologia deve ser interpretada também a partir da própria verdade, a partir da religião verdadeira e simples que podemos certamente encontrar entre os homens mais antigos.

Supõe-se que a essência do espírito infinito [unendlichen Geistes] deve ter sido originalmente revelada ao homem, mas de um modo simples, infantil e simbólico, especificamente como o Pai ou Rei que tudo cria e governa - uma ideia que nem mesmo a filosofia pode reprovar, e que muitas vezes tomou como auxílio, sempre que buscou demonstrar sua conviç̧ão sobre esse assunto e quando precisou abandonar os conceitos abstratos da escola. Supõe-se isso, e a partir dessas concepções simples e simbólicas é fácil encontrar a transição para toda mitologia - emprestamse forças naturais à divindade, a qual é personificada enquanto Pai-Filho, Rei-Servo, Cifra [Zahl], e, assim, abrem-se de uma vez as portas da fantasia; então, seguem-se naturalmente as mais variadas representações mitológicas, combinações e criações poéticas. Tudo, até mesmo o acaso contribui para enriquecer o círculo da mitologia. Tal reprodução acidental das divindades pode ser atribuída à antiga condição das línguas, a qual possibilitou que o epíteto de uma divindade cujo sentido havia se perdido, 
ou da qual se ouviu [o nome] em nações estrangeiras, neste ou naquele rito de adoração ou festa, tenha sido apropriada como uma nova divindade.

A perspectiva histórica, a qual reduz tudo a fatos, ou a perspectiva psicológica, que atribui tudo às invenções da fantasia, podem naturalmente explicar muita coisa, mas não são suficientes para compreender nenhuma mitologia; pois dificilmente se encontrará uma mitologia na qual não existam traços do verdadeiro conceito da divindade, mesmo que [este] se encontre desfigurado em razão de estranhas misturas. É certo que sem o simbólico, isto é, sem a relação com o Ser infinito, não existe mitologia alguma. Aliás, também o politeísmo e toda matéria que seja em si fabulosa nas diferentes mitologias, os conceitos principais [Hauptbegriff] e o fundamento da verdadeira religião não se opõem ao monoteísmo, nem lhe são irreconciliáveis. Além disso, desde que se compreenda a unidade divina enquanto totalidade [Allheit], e a totalidade apenas enquanto unidade [Einheit], encontraremos uma surpreendente prova histórica na mitologia hindu. Esta contém, de longe, muito mais matéria fabulosa do que a mitologia grega; a quantidade de divindades secundárias, das fábulas mais estranhas e de representações simbólicas é monstruosa, bem maior do que em qualquer outra mitologia. Ainda assim, em nenhuma outra mitologia pode-se encontrar um conceito tão claro e evidente do Ser mais elevado enquanto espírito infinito. Aqui, o conceito de unidade divina predomina inteiramente, do princípio ao fim, e as diversas manifestações poéticas e fábulas surgem apenas como expressão simbólica das forças naturais, ações e configurações que lhe são subordinadas. De fato, [na mitologia hindu] toda unidade é tanto seu conceito universal, como sua manifestação singular; mesmo os filósofos [acreditam que] é possível encontrar aqui, de uma forma muito nítida, a representação mais verdadeira da unidade divina enquanto Trindade; e ao lado dessa suprema ideia de uma religião verdadeira, muitas outras [ideias], como a encarnação [Menschwerdung], etc.

Desde que se considerem as diversas forças naturais representadas simbolicamente enquanto algo subordinado a $\mathrm{um}$ Ser infinito, o monoteísmo pode, em certa medida, ser muito bem associado ao politeísmo. Todavia, na mais antiga mitologia grega esse não era 
absolutamente o caso, e nesse ponto não é muito diferente da mitologia hindu. A mitologia homérica é [uma espécie] de politeísmo sem qualquer traço de monoteísmo, assim como mero antropomorfismo sem qualquer simbologia do universo e da natureza. Nela, o antropomorfismo é elevado à potência máxima, os deuses são meros homens, quase sem simbologia e relação com o infinito. As únicas alusões a um princípio superior em Homero são dois nomes de divindades, muitas das quais podem ser explicadas, enquanto outras, provavelmente de origem estrangeira, permanecem inexplicáveis. Os deuses nos quais encontra-se a alusão a algo elevado são Zeus, o Vivo, que leva os vivos; e Apolo, o Funesto - ou seja, Vida e Morte. Por essa razão, os homens em Homero também parecem irreligiosos. Porém, essa irreligiosidade não deve ser compreendida como mera oposição à religião, nem como incapacidade para a religião, mas sim como insuficiência, como ignorância infantil. Como é que se pode falar de incapacidade onde nenhuma religião foi ensinada? Os homens homéricos são tão irreligiosos quanto as crianças; ao mesmo tempo, como estas, eles demonstram vivacidade, delicadeza, receptividade, imparcialidade e a ingenuidade de sentimento, a qual se poderia chamar de religiosa.

O mesmo não ocorre com a mitologia grega da segunda época. Suas divindades são realmente mais sublimes e plenas de sentido do que as divindades homéricas; em todas as doutrinas, composições poéticas e configurações dos Mistérios existe certa relação com as forças da natureza e, nesse sentido, naturalmente, uma relação visível com o infinito.

Mas o equívoco foi [que nessa época] se permaneceu apenas na mera força da natureza; de um modo muito intenso e parcial, compreendiase o Ser infinito enquanto natureza e força viva, e não como espírito, como Eu infinito. Essa compreensão teve como consequência necessária a adoração da sensualidade absoluta; de fato, os gregos da época tardia se deixaram levar pela sensualidade mais ostensiva, opulenta e desregrada; [eles] consideravam essa sensualidade como a palavra mais sagrada e divina, ao acreditar que a liberdade e a alegria mais dissolutas, as quais predominavam em tais cerimônias religiosas, eram a melhor forma de representação e adoração da vida infinita da natureza. Essa sensualidade, 
a qual não se restringia apenas ao serviço religioso e às festas, mas que logo se alastrou por todo o caráter da nação, fornece uma explicação clara sobre a grande imoralidade como que sancionada por gregos e romanos da época tardia. É possível encontrar um exemplo parecido com essa sensualidade religiosa, embora extremo e inteiramente oposto, nas religiões bastante espirituais dos entusiasmados penitentes e ascetas, os quais - assim como os gregos da época tardia [o faziam] através da inteira devoção à sensualidade - acreditavam aproximar-se de Deus do modo mais complacente, através da completa mortificação de tudo o que fosse corporal e da absoluta autodestruição. Ambas [as crenças] são um entusiasmo equivocado. Em razão do contexto histórico, é entre os primeiros cristãos que essa aguda oposição se mostra de um modo ainda mais nítido. Essa espantosa degeneração de gregos e romanos tardios foi o que fez com que os cristãos, que surgiam ao mesmo tempo que eles, se opusessem [à sensualidade] de um modo ainda mais radical do que estava inscrito em sua religião, produzindo um ódio entre cristãos e pagãos e o desprezo exagerado por tudo o que fosse sensual e figurado, especialmente o que tivesse qualquer relação com gregos e romanos; decerto, devemos imputar mais a esse ódio do que à selvageria dos conquistadores bárbaros a adoração e a destruição de tantas obras da ciência e da arte.

Quanto ao surgimento dos Mistérios, não é possível comprovar historicamente nada de forma segura, pois, de modo a intensificar seu prestígio, sua origem foi situada nas épocas mais obscuras, a partir de alguma divindade (Orfeu, por exemplo). É provável que o início [de sua adoração] tenha ocorrido principalmente antes da introdução de Baco, Ísis ou Cibele. Aliás, é claro que foi o sentimento de irreligiosidade, ou melhor, de ausência de religião na mitologia homérica, o que ocasionou o surgimento dessa nova mitologia, mas, ao mesmo tempo, pelo fato de que o conceito de espírito infinito e divino está quase perdido, foi natural que se buscasse a plenitude infinita, a força e a vida da natureza. $\mathrm{O}$ mesmo costuma ocorrer entre homens para os quais aquele conceito [de espírito infinito e divino] não foi transmitido pelos pais ou mestres, mas que o descobriram por si mesmos, o que pode muito bem acontecer, 
como é o caso de muitos filósofos gregos, como Anaxágoras, Platão, Pitágoras, etc., mas esses são casos isolados no conjunto do povo. Alguns, os quais não quiseram ou puderam contentar-se apenas com conceitos filosóficos meramente abstratos, como, por exemplo, Pitágoras, buscaram realizar uma reforma nas ideias religiosas, introduzindo o culto simbólico do espírito infinito. Porém, essas foram as únicas tentativas. Outros, especialmente os filósofos tardios, desprezavam qualquer forma de mitologia, distanciando-se das crenças populares em geral, como aconteceu, de um modo semelhante, entre católicos e protestantes.

A tentativa dos tragediógrafos de moralizar a mitologia (a profanação dos Mistérios por Ésquilo) foi mal sucedida, bem como a tentativa dos filósofos de criar uma mitologia espiritual. Os tragediógrafos deram à mitologia uma moral muito elevada, mas nenhum misticismo, de modo que não foram capazes de aperfeiçoá-la.

Assim, a conclusão de nossa reflexão é que a mitologia grega nunca foi um todo satisfatório e coerente, mas sempre um caos de belos fragmentos e elementos míticos; e que, nos Mistérios, essa mitologia possuía o gérmen de uma perspectiva mais elevada do que nos poemas homéricos, mas também uma tendência predominantemente parcial e materialista, ao passo que a mitologia deve, sobretudo, ser universal, como a mitologia hindu, a qual unifica o que há de mais sensual na perspectiva grega com o que há de mais espiritual na filosofia.

Essa tendência ao materialismo entre os gregos (de que outro modo se pode chamar, de uma forma abstrata e filosófica, a aceitação e a adoração das forças produtivas da natureza, e a negação ou desconhecimento do espírito infinito?), que já se encontrava em Hesíodo e outros, em todas as suas Cosmogonias e Teogonias, as quais passaram dos Mistérios para a vida e a literatura, [essa tendência] teve uma influência prejudicial sobre toda sua formação [Bildung], pois o seu desenvolvimento, que seria abundante, diversificado e primoroso, tornou-se muito parcial e limitado. 


\section{Die griechische Mythologie (1803/1804) ${ }^{2}$}

Friedrich Schlegel

Sie zerfällt in zwei Epochen: die erste begreift die homerische, die älteste, die wir kennen, und wovon sich die Quellen meist nicht aufweisen lassen; die zweite enthält die Geschichte der Einführung fremder Gottheiten mit ihren Fabeln und Sagen. Schon die Art ihrer Einführung durch geheime Bruderschaften und sozusagen Missionarien gibt kund, da $\beta$ sie fremdartig und nicht einheimisch waren; dahin gehören z. B. Der Gottesdienst des Bacchus, den man in späterer Zeit von Phrygien hergebracht, und der der Isis, noch später von Ägypten entlehnt, vorzüglich auch die Mysterien dere Demeter zu Eleusis. Bei dieser Epoche müßte eigentlich zugleich das Verhältnis der Philisophen zur Mythologie erwähnt werden, welche dieselbe entweder ganz verwarfen oder ihr eine höhere Deutung zu geben suchten. Es kann indessen hier nicht unsere Zweck sein, die griechische Mythologie genau im einzelnen zu chrarakterisieren, sondern nur eine allgemeine Charakteristik und eine Prüfung und Beurteilung nach dem Begriff der Mythologie überhaupt ist hier an Ort und Stelle.

Der allgemeine Begriff der Mythologie, worüber alle einverstanden, ist ein Gemisch von Geschichte, mündlich fortgepflanzten Sagen, Sinnblidlichkeit und willkürlich hinzugefügter Dichtung. Nur Über den Ursprung der Mythologie und die Art, sie zu erklären, ist verschiedener Meinung. Einige wollen sie ganz historisch, andere gaz allegorisch erklären; schon bei den Alten finden sich diese beiden verschiedenen Ansichten. Eine dieser Ansichten allein auffassen, führt zur größten Eiseitigkeit. So unleugbar es ist, da $\beta$ in der alten Mythologie

\footnotetext{
${ }^{2}$ Texto publicado em Schriften und Fragmente: Ein Gesamtbild seines Geistes, obra de Friedrich Schlegel editada por Ernst Behler e publicada pela Alfred Kröner Verlag em 1956.
} 
Andeutungen auf die Naturkräfte und z. B. auf das Planetensystem enthalten sind, ebenso unleugbar ist es, da $\beta$ sich in derselben uralte wahrhafte Traditionen vom früheren Zustande der Menschen, von wunderbaren Taten großer Helden, von der Wanderung zahlreicher Völker, von der Stiftung und dem Untergang großer, mächtiger Reiche finden. Aber es ist noch nicht einmal hinreichend, beide Ansichten zu verbinden; es mu $\beta$ noch eine dritte, die philosophische, hinzukommen: die Mythologie mu $\beta$ auch aus der Wahrheit selbst, aus der wahrhaften, einfachen Religion, die wir bei den ältesten Menschen mit Sicherheit annehmen können, erklärt werden.

Man setz voraus, das Wesen des unendlichen Geistes sei dem Menschen ursprüglich offenbart worden, aber wie eseinfachen, kindlichen, sinnbildlichen Menschen offenbart werden mu $\beta$, als Vater und König nämlich, der alles erzeugt und regiert - eine Vorstellung, welche die Philosophie selbst nicht mißbilligen kann, sondern oft selbst zu Hilfe nehmen mußte, wenn sie ihre ganze Überzeugung über diesen Gegenstand aussprechen wollte und dazu die abstrakten Begriffe der Schule zu verlassen genötigt war. Man setzte dies voraus, und man wird von dieser einfachen, sinnbildlichen Vorstellung leicht den Übergang zur ganzen Mythologie finden - der Gottheit werden als Vater Kinder, als König Diener, Zahlen, personifizierte Naturkräfte beigegeben und hier mit einemal der Phantasie die Schranken eröffnet; es folgen die mannigfaltigsten mythologischen Darstellungen, Kombinationen und Dichtungen von selbst. Alles, selbst der Zufall, trägt dazu bei, den Kreis der Mythologie zu bereichern. Eine solche zufällige Vermehrung der Gottheiten ist z. B. Dem älteren Zustande der Sprachen beizumessen, der es möglich machte, da $\beta$ die einer Gottheit zukommenden Epitheta, deren Verständnis verloren war, oder die man bei fremden Nationen, bei diesen oder jenen gottesdienstlichen Handlungen und Festen gehört hatte, zu eigenen neuen Gottheiten wurden.

Die historische, alles auf Tatsachen, und die psychologische, alles auf Erfindungen der Phantasie zurückführende Ansichte der Mythologie kann freilich sehr vieles erklären, reicht aber bei keiner einzigen Mythologie aus; denn es wird sich schwerlich eine Mythologie auffinden 
lassen, in der nicht Spuren des wahren Begriffs der Gottheit, wenngleich durch fremdartige Beimischungen entstellt, vorhanden wären. Ohne alles Sinnbildliche, d. h. Ohne alle Beziehung auf das unendliche Wesen, auf die Naturkräfte usw., ist gewi $\beta$ keine Mythologie. Übrigens ist auch der Polytheismus und all das Fabelhafte aus sich in den verschiedenen Mythologien dem Hauptbegriff und der Grundlage der wahren Religion, dem Monotheismus, nicht gerade entgegengesetzt und mit ihm unverträglich. Außerdem, da $\beta$ dies philosophisch zu erweisen, insofern man die Einheit Gottes nicht anders als Allheit, dieser aber wieder nur als Einheit richtig denken kann, haben wir in der indischen Mythologie einen auffallenden historisches Beweis davon. Diese enthält bei weitem mehr Fabelhaftes als die griechische; die Menge der Untergottheiten, der sonderbarsten Fabeln und sinnbildlichen Darstellungen ist ungeheuer, ja größer wohl als in irgendeiner anderen Mythologie. Und doch findet sich in keiner ein so ganz klarer, deutlicher Begriff von dem höchsten Wesen als unendlichem Geist. Der begriff der Einheit Gottes herrscht hier durchaus von Anfang bis zu Ende, die verschiedenen Dichtungen und Fabeln erscheinen nur als sinnbildliche Einkleidungen der untergeordneten Naturkräfte, Wirkungen und Gestalten. Und zwar ist jene Einheit nicht nur der allgemeine Begriff der Einheit, sondern die besondere, auch dem Philosophen wahrhafteste Vorstellung der göttlichen Einheit als Dreieinigkeit finden sich hier laut und bestimmt ausgesprochen, und neben dieser vorzüglichsten Idee der Wahren Religion noch mehrere andere, die der Menschwerdung usw. Monotheimus kann also in einem gewissen Grade, insofern nämlich die verschiedenen sinnbildlich dargestellten Naturkräfte als denn einen Unendlichen untergeordnete Wesen betrachtet werden, ganz gut mit Polytheismus verbunden sein. Bei der älteren griechischen Mythologie war das aber durchaus nicht der Fall, und es ist wohl hierin keine verschiedener von der indischen. Die homerische Mythologie ist Polytheismus ohne allen Monotheismus und bloßer Anthropomorphismus ohne alle Symbolik des Universums und der Natur. Der Anthropomorphismus ist hier aufs allerhöchtens getrieben, die Götter sind bloße Menschen, fast ohne alle Sinnbildlichkeit und Beziehung auf das Unendliche. Die einzigen Andeutungen eines höheren 
Prinzips bei Homer sind zwei in der Namen der Gottheiten, deren sich mehrere erklären lassen, andere aber nicht, die denn wahrscheinlich fremden Ursprungs sein mögen. Die beiden, die eine höhere Hinweisung enthalten, sind Zeus, der Lebendige und lebendig Nehmende, und Apollon, der Verderber, also gleichsam Leben und Tod. Daher erscheinen auch die homerischen Menschen gewissermaßen irreligiös. Diese Irreligiosität ist aber nicht als Entgegensetzung gegen die Religion, auch nicht als Unfähigkeit zur Religion, sondern vielmehr als Mangel, als kindliche Unwissenheit zu betrachten. Wie kann von Unfähigkeit die Rede sein, wo keine Religion gelehrt worden ist! Die homerischen Menschen sind irreligiös, wie Kinder es sind, dagegen zeigen, sie so wie diese eine Regsamkeit, Zartheit, Empfänglichkeit, Unbefangenheit und Naivität des Gefühls, die man religiös nennen könnte.

Anders verhält es sich mit der griechischen Mythologie der zweiten Epoche. Die Gottheiten derselben sind wirklich erhabener und sinnvoller als die homerischen; in allen Lehren, Gedichten und Einrichtungen der Mysterien ist eine bestimmte Beziehung auf die Naturkräfte und insoweit freilich eine Beziehung auf das Unendliche sichtbar. Aber der Fehler war, da $\beta$ man hier bei der bloßen Naturkraft stehenblieb, man faßte das unendliche Wesen zu sehr und zu ausschließlich als unendliche Natur und Lebenskraft, nicht als Geist davon, als unendliches Ich auf. Dies mußte notwendig auf die Verehrung absoluter Sinnlichkeit führen, wie denn auch wirklich die späteren Griechen in die allerauffallendste, üppigste aud ausschweifendste Sinnlichkeit gerieten und diese selbst als das heiligste, gottgefälligste Wort ansahen, indem sie nähmlich die höchste ungebundenste Freiheit und Freude, die bei solchem Gottesdienst herrschte, für die beste Darstellung und Verehrung des unendlichen Lebens der Natur hielten. Diese Sinnlichkeit, dis sich nicht allein auf den Gottesdienst und die Feste beschränkte, sondern natürlich bald auf den ganzen Charakter der Nation überging, erklärt leicht die bei den späteren Griechen und Römern gleichsam sanktionierte große Unsittlichkeit. Ein ähnliches, dieser religiösen Sinnlichkeit durchaus entgegengesetztes Extrem finden wir in ganz geistigen Religionen bei schwärmenden Büßern und Asketen, die, so wie jene durch gänzliche Hingebung an die 
Sinnlichkeit, so durch gänzliche Abtötung alles körperlichen und absolute Selbsvernichtung sich Gott am gefälligsten zu machen glauben. Beides ist ein Mißverstandener Enthusiasmus. Am auffallendsten zeigt sich dieser schneidende Gegensatz, wegen des historischen Zusammenhangs, bei den ersten Christen. Eben jene außerordentliche Ausartung der späteren Römer und Griechen mußte die neben ihnen aufkommenden Christen mehr noch, als es in ihrer Religion lag, auf das Entgegesetzte werfen und den $\mathrm{Ha} \beta$ zwischen Christen und Heiden und die übertriebene Verachtung alles Sinnlichen und Bildlichen, besonders dessen, was nur irgendeinige Beziehung mit den Griechen und Römer hatte, hervorbringen, dem wir gewi $\beta$ mehr als der Roheit der einwandernden Barbaren die Verheerung und Zerstörung so vieler Werke der Wissenschaft und Kunst zuzuschreiben haben.

Was das Entstehen der Mysterien betrifft, so läßt sich historisch nichts Gewisses nachweisen, weil man sie, um ihnen Ansehen zu verschaffen, absichtlich aus den dunkelsten Zeiten und vom irgendeiner Gottheit (Orpheus z. B.) herschrieb. Hauptsächlich mögen sie wohl ihren Anfang von der Einführung der Bacchus, Isis und Cybele gewonnen haben. Übrigens ist klar, da $\beta$ gerade das Gefühl der Irreligion, oder vielmehr des Mangels an Religion, in der homerischen Mythologie das Entstehen dieser neuen Mythologie veranlaßte, zugleich aber auch, da $\beta$ man, weil der Begriff des unendlichen göttlichen Geistes so gut als verloren war, natürlich auf die unendliche Fülle, die Kraft und das Leben der Natur fallen mußte - wie es bei Menschen, denen jener Begriff nicht von ihren Vätern oder Lehrern übertragen worden, zu gehen pflegt, wenn sie ihn nicht aus sich selbst finden, welches jedoch allerdings möglich und auch bei vielen griechischen Philosophen, bei Anaxagoras, Plato, Pitagoras usw. der Fall war, die aber unter ihrem ganzen Volke einzeln allein standen. Einige, die bei den blo $\beta$ abstrakten philosophischen Begriffen nicht bleiben wollten und konnten, wie z. B. Pythegoras, suchten eine Reformation in den religiösen Ideen zu bewirken und einen sinnbildlichen Gottesdienst des unendlichen Geistes einzuführen. Es bliebe aber blo $\beta$ bei diesen Versuchen. Die anderen, besonders die späteren Philosophen, verachteten alle Mythologie und trennten sich 
so vom allgemeinen Volksglauben, da $\beta$ ein Verhältnis ähnlich dem der katholiken und Protestanten entstand. Die Versuch der Tragiker, die Mythologie zu moralisieren (Äschylos` Profanierung der Mysterien), mißlangen ebenso wie die Versuche der Philosophen, eine neue geistige Mythologie hervorzubringen. Die Tragiker legten wohl eine höhere Moralität in die Mythologie, aber keine Mystik, und konnten sie nicht im Grunde bessern.

Und so ist denn das Resultat unserer Betrachtung, da $\beta$ die griechische Mythologie nie ein befriedigendes und übereinstimmendes Ganzes gewesen, sondern immer nur ein Chaos von schönen mythischen Bruchstücken und Elementen geblieben, die in den Mysterien zwar den Keim zu einer höheren Ansicht als in den homerischen Gedichten enthielten, aber hauptsächlich eine ganz einseitige materialistische Tendenz hatten - während doch die Mythologie vor allen Dingen universell sein soll wie die indische, die das Sinnlichste der griechischen Ansicht mit dem Geistigsten der Philosophie vereinigt (wie kann man die alleinige Annahme und Verherung der produktiven Naturkraft mit Leugnung oder Unkenntnis eines höchsten unendlichen Geistes abstrakt philosophisch ausgesprochen - anders nennen), diese Tendenz, die sich schon bei Hesiod und so fort in allen ihren Kosmogonien und Theogonien findet und aus den Mysterien ins Leben und die Literatur überging, hat einen schädlichen Einflu $\beta$ auf ihre ganze Bildung gehabt, indem sie derselben nämlich bei ihrer sonstigem reichen, mannigfaltigen Entwicklung und hohen Vortrefflichkeit eine gar große Einseitigkeit und Beschränktheit gegeben.

Recebido em: 17 de setembro de 2018. Aprovado em: 16 de outubro de 2018. 